Received: 26 October 2017

Accepted: 19 December 2017

Published online: 11 January 2018

\section{Hydrological simulation and uncertainty analysis using the improved TOPMODEL in the arid Manas River basin, China}

\begin{abstract}
Lianqing Xue ${ }^{1,2,3,5}$, Fan Yang ${ }^{1}$, Changbing Yang ${ }^{3}$, Guanghui Wei ${ }^{4}$, Wenqian $\mathrm{Li}^{2}$ \& Xinlin $\mathrm{He}^{2}$
Understanding the mechanism of complicated hydrological processes is important for sustainable management of water resources in an arid area. This paper carried out the simulations of water movement for the Manas River Basin (MRB) using the improved semi-distributed Topographic hydrologic model (TOPMODEL) with a snowmelt model and topographic index algorithm. A new algorithm is proposed to calculate the curve of topographic index using internal tangent circle on a conical surface. Based on the traditional model, the improved indicator of temperature considered solar radiation is used to calculate the amount of snowmelt. The uncertainty of parameters for the TOPMODEL model was analyzed using the generalized likelihood uncertainty estimation (GLUE) method. The proposed model shows that the distribution of the topographic index is concentrated in high mountains, and the accuracy of runoff simulation has certain enhancement by considering radiation. Our results revealed that the performance of the improved TOPMODEL is acceptable and comparable to runoff simulation in the MRB. The uncertainty of the simulations resulted from the parameters and structures of model, climatic and anthropogenic factors. This study is expected to serve as a valuable complement for widely application of TOPMODEL and identify the mechanism of hydrological processes in arid area.
\end{abstract}

The deterioration of aquatic ecosystems due to changeable hydrological processes is an ongoing issue in many basins world widely ${ }^{1-4}$. Hydrological processes are affected by complex factors such as soil properties, land use type, climate, and topographic conditions and vary spatially and temporally ${ }^{5-7}$. Therefore, prediction of water resource availability is a difficult problem restricted by the implementation of water shortages and integrated river basin management in many basins ${ }^{8,9}$. Hydrological models are efficient tools to create new management strategies for better utilizing current hydrological theories ${ }^{10-13}$.

Numerous watershed hydrologic models have been adopted for the simulation of streamflow in the last decades to solve watershed problems ${ }^{14}$. These models include Soil and Water Assessment Tool (SWAT), and Hydrological Simulation Program Fortran (HSPF) and semi-distributed Topographic hydrologic model (TOPMODEL). Xie and Lian (2013) compared the performance of hydrologic simulation of HSPF and the SWAT model in the USA and found that HSPF can generate more accurate discharge predictions ${ }^{15}$. Although many models are powerful and efficient for solving watershed problems, they are difficult to calibrate when considering various hydrology and water quality processes, especially in the arid area ${ }^{16,17}$. Low vegetation coverage, thick aeration zone and unique climatic conditions contribute to the complicated hydrological processes in arid area. TOPMODEL is widely used all over the world ${ }^{18}$, but rarely consider the influence of topographic index and snowmelt on watershed runoff.

As an excellent representation of semi-distributed models, TOPMODEL is popular and widely used in watershed scales ${ }^{19-21}$. The semi-distributed Topographic hydrologic model (TOPMODEL) is a rainfall runoff model based on a simple theory of watershed hydrological similarity, with the topographic index as the index of hydrological similarity ${ }^{22-24}$. To improve the applicability of TOPMODEL in the Manas River, the internal tangent circle

${ }^{1}$ Hydrology and Water Resources College, Hohai University, Nanjing, 210098, P. R. China. ${ }^{2}$ Shihezi University, Shihezi, 832003, P. R. China. ${ }^{3}$ Jackson School of Geosciences, University of Texas at Austin, Austin, 78712, USA. ${ }^{4}$ Tarim River Basin Administration, Korla, 841000, P. R. China. ${ }^{5}$ Hohai University Wentian College, Maanshan, 243000, P. R. China. Correspondence and requests for materials should be addressed to L.X. (email: Iqxue@hhu.edu.cn) 


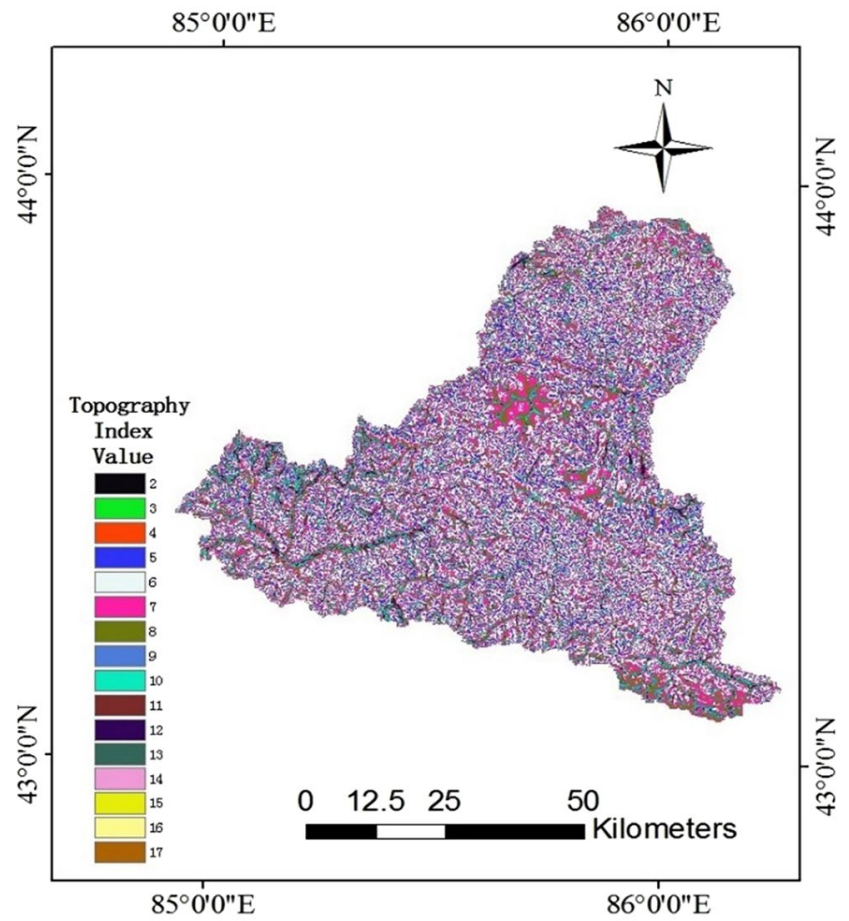

Figure 1. Distributed topographical indexes of the upper Manas River basin (Note: the map was generated using ESRI's ArcGIS (version 10.1).

on a conical surface method proposed by Yong (2009) is used for computing topographic index distribution in this paper $^{24}$. Furthermore, this paper includes the consideration of solar radiation and calculates the snowmelt using the improved temperature index coupled with TOPMODEL ${ }^{25-28}$. There are three general aspects contributing to uncertainty in hydrology: uncertainty in hydrological phenomena, model structures, and parameter estimation $^{29-32}$. Beven (1992) proposed generalized likelihood uncertainty estimation (GLUE) method to estimate hydrological uncertainty, which represents the latest developments in this field ${ }^{33,34}$. Therefore, the uncertainty of model parameters is studied using the GLUE method.

The mechanism of water movement in an arid area seems complicated ${ }^{35,36}$. The Manas River Basin (MRB) has been experienced water scarcity, resulting in conflicts among water consumers at upstream and downstream regions, and degradation of its natural ecosystems ${ }^{37}$. The functions of river ecosystem has been significantly influenced by the climate change, irrational exploitation and utilization of water resources, such as irrigation and dam construction in the MRB ${ }^{38}$. The objective of this study is to simulate hydrological process using the improved TOPMODEL considering snowmelt and topographic index and identify the sensitive parameters for flow in the $\mathrm{MRB}, \mathrm{China}$. These results are expected to help us to further understand the mechanism of water movement in the arid area supplied from glaciers and snowmelt, generate more accurate discharge predictions and help planners to establish effective water utilization and allocation policies.

\section{Results}

Calculationz of topographical index. The single-flow direction algorithm is adopted for the calculation of the topographical index based on the digital elevation model (DEM). Since the grid points with similar topographical index have the same characteristic of hydrological response in TOPMODEL, the operating efficiency of the model will be improved in the region after the division of hydrological response units. It is not necessary to simulate the topographical index in all grids due to the similarity of the topographical index. The distribution function in the whole basin is generated by a statistical method with different topographical index values (Fig. 1). In this study, the region is segmented into 25 sections based on the topographical indexes, and the relationship of area ratios of topographical index is shown in Fig. 2. The minimum, maximum, mean, standard deviations of the topographical index are $2.9,17.9,10.3$ and 4.5 , respectively.

Model Calibration and Validation. The mountain region in the MRB illustrates vertical characteristics obviously. As the temperature decreases with rising elevation, the elevation has a great influence on snowmelt. To simplify the problem, we divide the mountain region vertically considering snow distribution and characteristics. The basin can be divided into three altitudinal belts. As shown in Table 1 and Fig. 3, regions with the altitude above $3600 \mathrm{~m}$ are defined as District $\mathrm{C}$ with high coverage of snow. Average ambient temperature in District $\mathrm{C}$ is below $0{ }^{\circ} \mathrm{C}$. The region with altitude $1800 \sim 3600 \mathrm{~m}$, district $\mathrm{B}$, is the middle mountain area with patchy discontinuous coverage of snow. Regions below $1800 \mathrm{~m}$ are called district $\mathrm{A}$.

The daily runoff data from 2006 to 2008 were chosen as the calibration periods, while 2009 and 2011 were determined as validation periods. Monte Carlo was used to generate model parameters randomly. The upper 


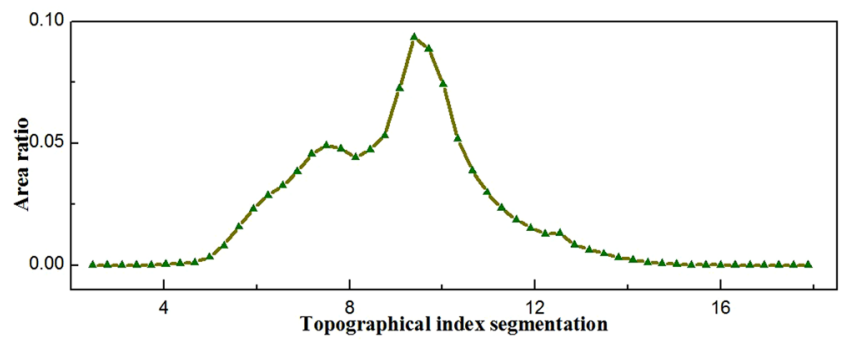

Figure 2. Plot of topographical index versus area ratio in the upper Manas River basin.

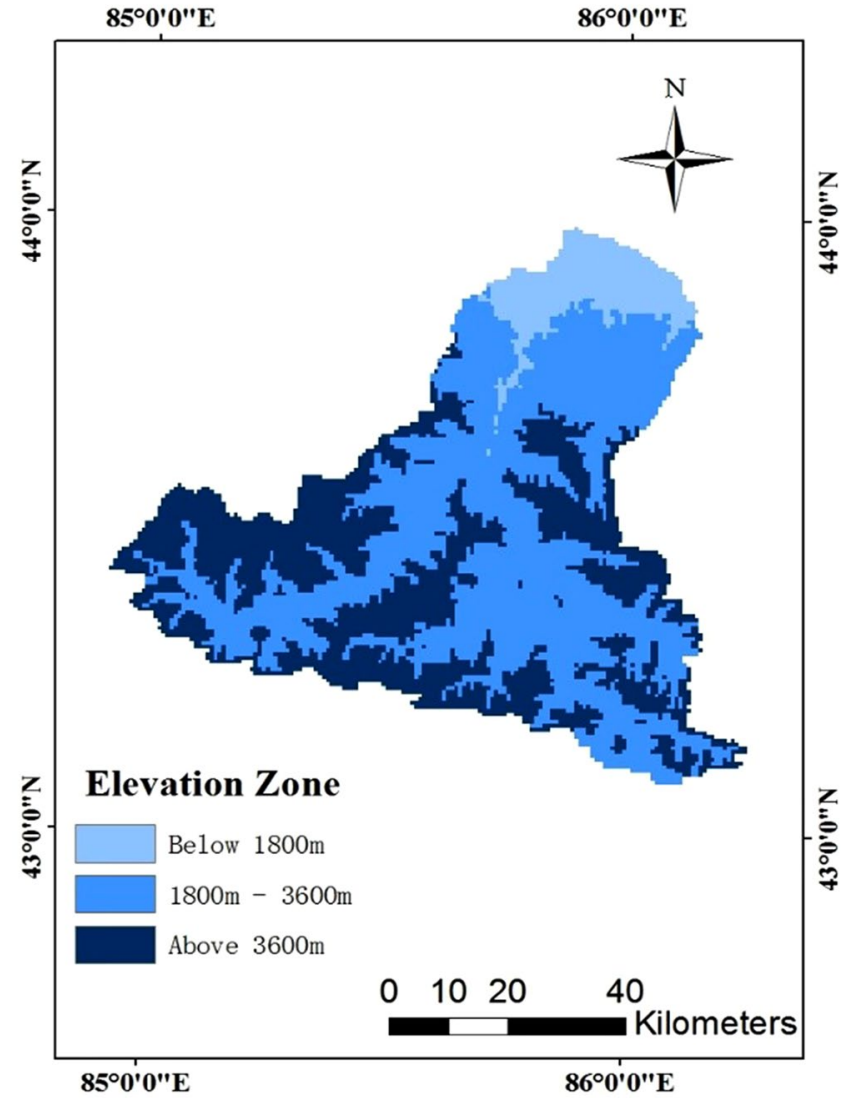

Figure 3. Vertical elevation of the mountain region in the Manas River Basin (Note: the map was generated with data available from the Chinese Geospatial Data Cloud using ESRI's ArcGIS (version 10.1; http://www. gscloud.cn/).

\begin{tabular}{|l|l|l|l|}
\hline Elevation(m) & Altitude zone & Area $\left(\mathbf{k m}^{2}\right)$ & Snow cover features \\
\hline$<1800$ & A & 416.17 & $\begin{array}{l}\text { The instantaneous porphyritic } \\
\text { discontinuous snow belt }\end{array}$ \\
\hline $1800 \sim 3600$ & B & 2740.17 & Patchy discontinuous snow belt \\
\hline$>3600$ & C & 1956.27 & Glacial and permanent snow \\
\hline
\end{tabular}

Table 1. The three vertical distribution of the mountain region in the Manas River Basin.

and lower limit for each sensitive parameter was obtained according to the historical data (Table 2). After setting the initial range, the parameters were calibrated using the variable domain decreasing algorithm. Figure 4 illustrates the simulated streamflow of the snowmelt-rainfall runoff model, the comparison of simulated and observed values and the general correlation between rainfall and runoff during the period of 2006 to 2008 . After manual adjustment of the parameters, the coefficients of determination from 2006 to 2008 are $0.81,0.61$ and 


\begin{tabular}{|l|l|l|l|l|l|}
\hline Parameters & $\mathbf{S R}_{\max /}(\mathbf{m})$ & $\mathbf{S R}_{\mathbf{0}} /(\mathbf{m})$ & $\mathbf{S Z M} /(\mathbf{m})$ & $\mathbf{T}_{\mathbf{0}} /\left(\mathbf{m}^{2} \cdot \mathbf{h}^{-1}\right)$ & $\mathbf{R V} /\left(\mathbf{m} \cdot \mathbf{h}^{-1}\right)$ \\
\hline Value & 0.0301 & 0.0116 & 0.0464 & 3.4827 & 2329.194 \\
\hline
\end{tabular}

Table 2. Parameters of the diurnal simulation. Notes: $\mathrm{SR}_{\max }, \mathrm{SR}_{0}, \mathrm{SZM}, \mathrm{T}_{0}, \mathrm{RV}$ represent maximum water storage capacity in the root zone, initial saturated water shortage, exponential decay rate, effective infiltration rate, and effective overland flow runoff rate, respectively.
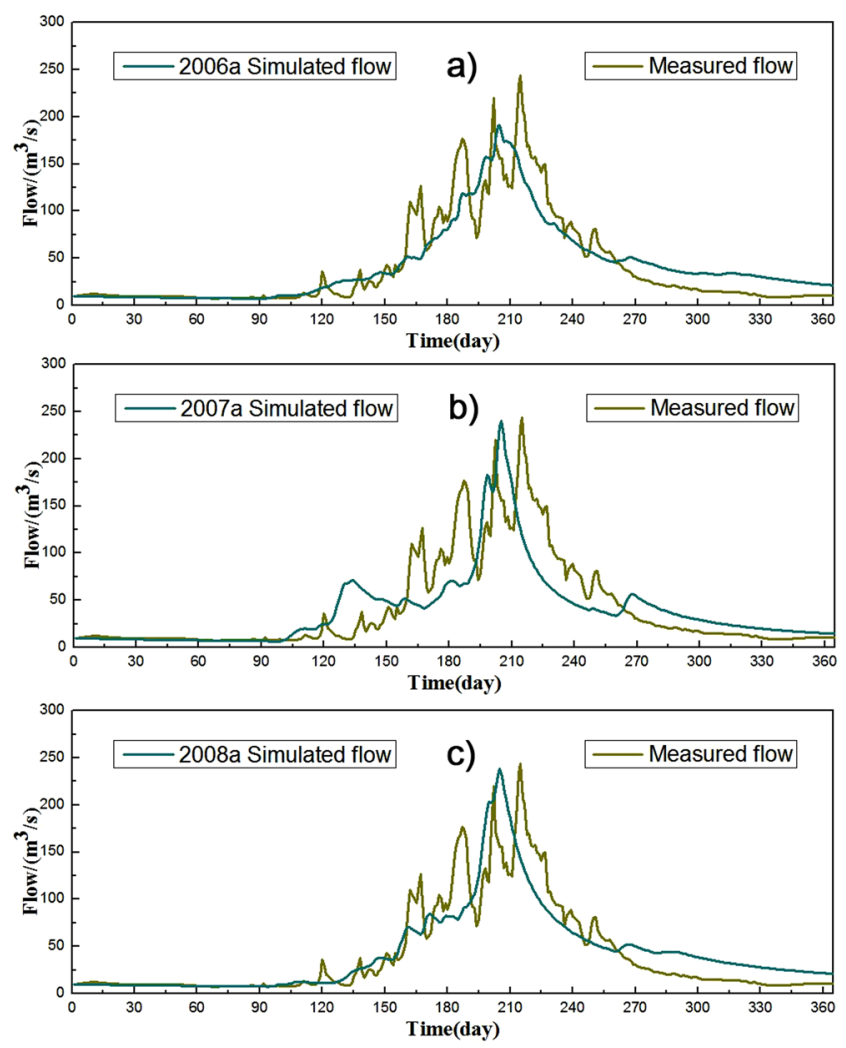

Figure 4. Daily runoff in the Manas River during the calibration period (during a) 2006 to c) 2008).

0.75 , respectively. Figure 5 shows the comparison of simulated and observed values and the general correlation between rainfall and runoff in the validation period. The coefficients of determination for the validation data (in 2009 and 2011) were 0.76 and 0.73 , respectively. Therefore, the simulated result is significantly influenced by the accuracy of the snowmelt calculation. The results in the study reveal that the model performance is acceptable and comparable to runoff simulation.

Uncertainty Analysis of the Model Parameters. The parameter sets with a sample size of 10,000 were generated through the Monte Carlo simulations based on the assumption of uniform distributions. The GLUE analysis was adopted to the simulation of daily runoff, and deterministic coefficient is chosen as the likelihood criterion. Table 3 shows the relationship between the parameters and likelihood value of the simulation of daily runoff. From the differences between certainty factor value and five parameters, it was found that four parameters $\left(\mathrm{SR}_{\max }, \mathrm{SR}_{0}, \mathrm{~T}_{0}\right.$, and $\left.\mathrm{RV}\right)$ are not sensitive for the runoff simulation. However, Fig. 6 shows that the exponential decay rate of SZM parameter has a significant impact on the simulation results. It indicated that the SZM is a sensitive parameter for the runoff simulation. Moreover, the value of SZM parameter is convergent to 0.0464 in the simulation finally.

In this study, the simulations with likelihood value less than the threshold value of the parameters are considered to be zero, while the likelihood value larger than the threshold value of the parameters are normalized and sorted according to the simulated streamflow. Figure 7 shows the comparisons of the flood simulation results calculated with different conditions, including observations in 2006 and streamflow with the confidence interval of $95 \%$ and $5 \%$. It indicated that the runoff simulation falls mostly within the $95 \%$ confidence interval except several peaks. However, the runoff simulation exceeds the $5 \%$ confidence interval almost three months in 2006.

\section{Discussion}

In the current study, the topographical index was calculated using the geometric cone inscribed circle method. Figures 4 and 5 illustrate that the subsequent distribution of the topographical index is more intensive, with 

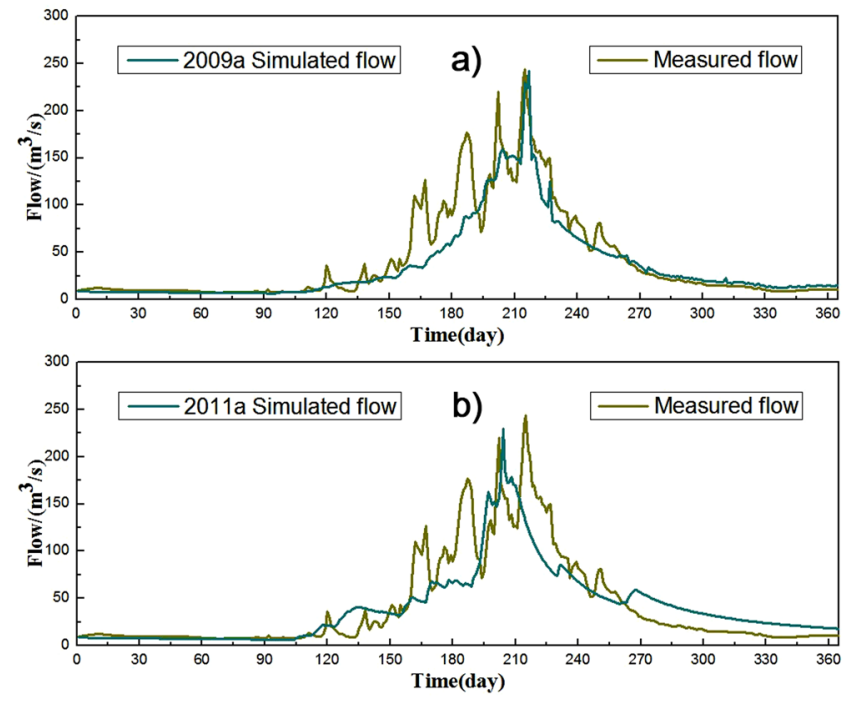

Figure 5. Daily runoff in the Manas River during the validation period (in a) 2009 and b) 2011).

\begin{tabular}{|l|l|l|l|}
\hline Parameter & Minimum & Maximum & Average \\
\hline $\mathrm{SR}_{\max }$ & 0.01 & 0.1 & 0.055 \\
\hline $\mathrm{SR}_{0}$ & 0 & 0.02 & 0.001 \\
\hline $\mathrm{SZM}$ & 0.01 & 0.1 & 0.055 \\
\hline $\mathrm{T}_{0}$ & 0.1 & 5 & 2.553 \\
\hline $\mathrm{RV}$ & 2000 & 3500 & 2750 \\
\hline
\end{tabular}

Table 3. The value range of TOPMODEL parameters. Notes: $S_{\max }, S R_{0}, S Z M 、 T_{0}, R V$ represent maximum water storage capacity in the root zone, initial saturated water shortage, exponential decay rate, effective infiltration rate, and effective overland flow runoff rate, respectively.

higher topographical index concentrated in the high mountain regions. It is signified that the regions with intensive distribution of the topographical index have high runoff accumulation trends. We employed an improved temperature indicator to calculate snowmelt, including influential factors such as surface radiation coefficient, glacier surface, sky permittivity, variation in solar radiation, and elevation. The calculated snowfall was input to TOPMODEL as the precipitation. After the several trials, the model application results illustrate that simulated result would be influenced by the precision of the snowmelt factor. Our results conclusively reveal that the model performance is acceptable and comparable to runoff simulation. However, accuracy of meteorological data may have a certain impact on the results of the model. Some errors may be related to the complex conditions of the climate and the underlying surface.

All the methods and data in this study are the respective influencing factors in the simulation. Evaporation data is obtained from the hydrological data at Ken Swart station. The improved degree-day method is adopted to calculate rainfall and snowmelt. Runoff is simulated by the topographical index curve and the geometric cone method. Moreover, the effect of parameters in TOPMODEL is also an important influencing factor to streamflow simulation. The selection range of the parameters is subjectively defined. In this study, the parameter debugging is manual. It implies that the parametric optimization may be not accurate and need for further study. All these factors may affect the simulation results and increase the processing uncertainty to the forecasting model.

Parameter equifinality is of great uncertainty to choose the so-called optimal parameter values. Parameter equifinality is resulted from the greater relevance of the model parameters, the defects of hydrological model structure and the complicated hydrological processes within the basin. In the current study, the parameter sets are randomly selected using Monte Carlo method. The sampling process could not be rigorous, otherwise performance period of the model will increase hugely. Therefore, shorter performance period allows the possibility of non-optimal sample sets, while reduces the accuracy of the simulation.

The impact of climate change and human activities has become great challenges for the simulation of streamflow $^{39}$. The uneven distribution of rainfall, evaporation and temperature variation may affect the temporal and spatial characteristics of water resources. In fact, temperature and precipitation increased significantly and potential evapotranspiration showed a decreasing trend ${ }^{37}$. In this study, it can be focused on climate change effects on hydrological processes with snow accumulation (thickness) and snowmelt mechanism in the MRB. As for human activity, cultivated area expansion, agricultural irrigation and dam construction are the respective factors in the $\mathrm{MRB}^{40,41}$. Many researches revealed that more and more ecological water is consumed for the excessive expansion of irrigated area and agricultural water consumption is still climbing at an alarming rate despite the gradually 

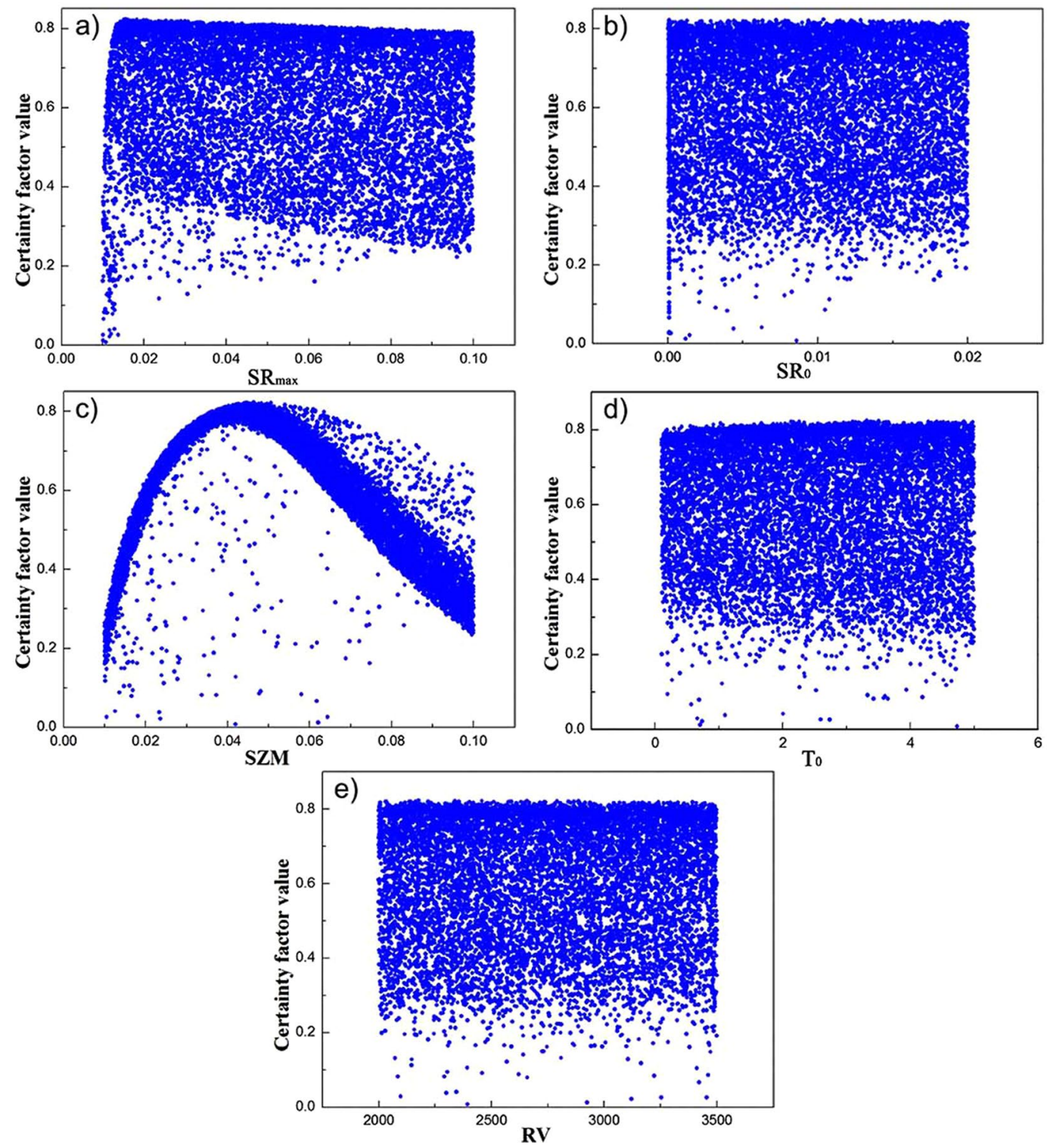

Figure 6. Dotty plots of parameters about $(\mathbf{a}) \mathrm{SR}_{\max },(\mathbf{b}) \mathrm{SR}_{0},(\mathbf{c}) \mathrm{SZM},(\mathbf{d}) \mathrm{T}_{0}$, and (e)RV in the GLUE analysis(Notes: $\mathrm{SR}_{\max }, \mathrm{SR}_{0}, \mathrm{SZM}, \mathrm{T}_{0}, \mathrm{RV}$ represent maximum water storage capacity in the root zone, initial saturated water shortage, exponential decay rate, effective infiltration rate, and effective overland flow runoff rate, respectively).

improved water use efficiency and reformed irrigation management ${ }^{38}$. Meanwhile, reservoir construction has become great challenges for the sustainable development of water resources in the MRB. Therefore, it is unequivocally clear that the uncertainty from climate change and human activity may reduce the accuracy of runoff simulation consequently.

\section{Materials and Methods}

Study area. The MRB $\left(85^{\circ} 01^{\prime} \sim 86^{\circ} 32^{\prime} \mathrm{E}, 43^{\circ} 27^{\prime} \sim 45^{\circ} 21^{\prime} \mathrm{N}\right)$ is located at the northern foot of the Tianshan Mountains in Xinjiang, and along the southern margin of the Junggar Basin (Fig. 8). The total area of the MRB is $1.98 \times 10^{4} \mathrm{~km}^{2}$, while the plain area is $1.46 \mathrm{~km}^{2}$. The region has middle temperate continental arid climate, with a vertical climate change characteristic. The streamflow mainly comes from snowmelt and precipitation ${ }^{42}$. The precipitation distribution is uneven due to the influence of water vapor sources, topography, and latitude. Snowmelt water in Tianshan Mountain accounts for $47 \%$ of the annual volume of streamflow in the MRB. The streamflow generates in the mountain area, and dissipates in the plain area ${ }^{43}$. The Ken Swart hydrological station $\left(43^{\circ} 58^{\prime}, 85^{\circ} 57^{\prime} \mathrm{E}\right)$ was started in 1955 , and measured various hydrological parameters for the Manas river region. The MRB is a typical comb-like river system, with runoff distribution in the mountains above the mountain-pass, and loss below the mountain-pass. 


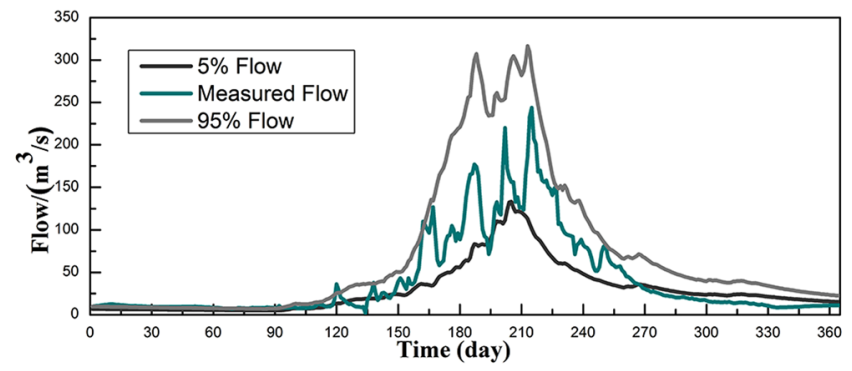

Figure 7. Uncertainty of the daily module in the Manas River Basin in 2006.

Data. Annual hydrological and meteorological data were collected from the Ken Swate hydrologic station, including precipitation, temperature, evaporation, streamflow, and so on. The simulation period was from 1 th January, 2006 to 31th December, 2011. However, the data in 2010 is not complete, the series of streamflow excludes the data in 2010. Since the catchment area of the upper MRB is not large, the precipitation, evapotranspiration, runoff, and temperature data from the Ken Swart hydrologic station were used to represent the whole region. The calibration period was 1th January, 2006 to 31th December, 2008, and the validation period was 1th January, 2009 to 31th December, 2011 (excluding 2010).

Land use and vegetation data were collected from resources and environment science data center in Chinese academy of sciences (http://www.resdc.cn). Land use and vegetation cover changes cause consequential changes in local energy and water balance, and have effects on surface runoff, including the kinetic and potential energy, and the time and space distribution of the runoff. The difference of climate, underlying surface condition, the vegetation types and the rainfall intensity also have a profound influence on regional hydrological processes ${ }^{20,44}$. Therefore, the mechanism of runoff generation is studied under the condition of different land types. Seen from Table 4, this study classified the land types using the land resource classification method proposed by Chinese Academy of Sciences (CAS).

The classification of Table 4 is not the only possible option. To meet the objectives of a given study, classification is often combined with the land vegetation cover types and region, which allows deeper segmentation ${ }^{27}$.

Methods. The hydrologic model. TOPMODEL is a physically based semi-distributed model for streamflow simulation, and has been widely used since $1970^{23,45}$. In this study, the TOPMODEL is used as a reference tool for simulating hydrological process in the MRB. In this hydrological model, the basin topography index is used to describe and explain the trend and movement of streamflow along the slope caused by gravity drainage. The soil of any place in the basin is divided into three different water-bearing zones: vegetation root zone $\left(S_{r z}\right)$, unsaturated zone $\left(S_{u z}\right)$, saturated zone $\left(Z_{i}\right)$.The basin was divided into grids by the digital elevation model. The hydrokinetic process for each cell is shown in Fig. 9. After the precipitation $(P)$ satisfied the interception of plant canopy and filled the hollow, it infiltrates into the plant root zone and supplies the water shortage first. Some of the moisture stored in this zone evaporates while the remainder $\left(q_{v}\right)$ moves into the unsaturated soil zone, infiltrating vertically at some speed. In the saturated underground water zone, moisture moves laterally and forms a subsurface flow $\left(q_{b}\right.$ (also called base flow)). The surface of saturated underground water varies with time due to the moisture infiltration and subsurface flow. If the level of underground water rises to the surface of ground, it forms a saturated surface, and produces a saturated slope flow $\left(q_{s}\right)$. Runoff occurs in saturated surface areas or source areas. The total moisture displacements, $Q_{b}$ and $Q_{s}$, can be obtained according to the formulas (2) and (3). Thus, in TOPMODEL, the total runoff $(Q)$, is the sum of subsurface and slope flows,

$$
\begin{gathered}
Q=Q_{b}+Q_{s} \\
Q_{s}=\frac{1}{\Delta t} \sum_{i} \max \left(\left[S_{u z, i}-\max \left[Z_{i}, 0\right]\right], 0\right) A_{i} \\
Q_{b}=Q_{0} \cdot e^{-\bar{Z} / S_{z m}} \\
Q_{0}=A T_{0} \cdot e^{-\lambda^{*}} \\
\lambda^{*}=\frac{1}{A} \int_{0}^{A} \ln \left(\frac{\alpha_{i}}{\tan \beta_{i}}\right) \mathrm{d} A
\end{gathered}
$$

where $A_{i}$ can be obtained by the curve between topographical index and area ratio in the upper Manas River basin (Fig. 2), $\Delta t$ is the time step, $\lambda$ is the topography index, $S_{z m}$ is the maximum of the depth of water storage in unsaturated areas, $T_{0}$ is the effective infiltration rate. Normally, the time step is one hour in TOPMODEL. However, considering the observational data in the mountain regions, we used a time step of one day. There were 


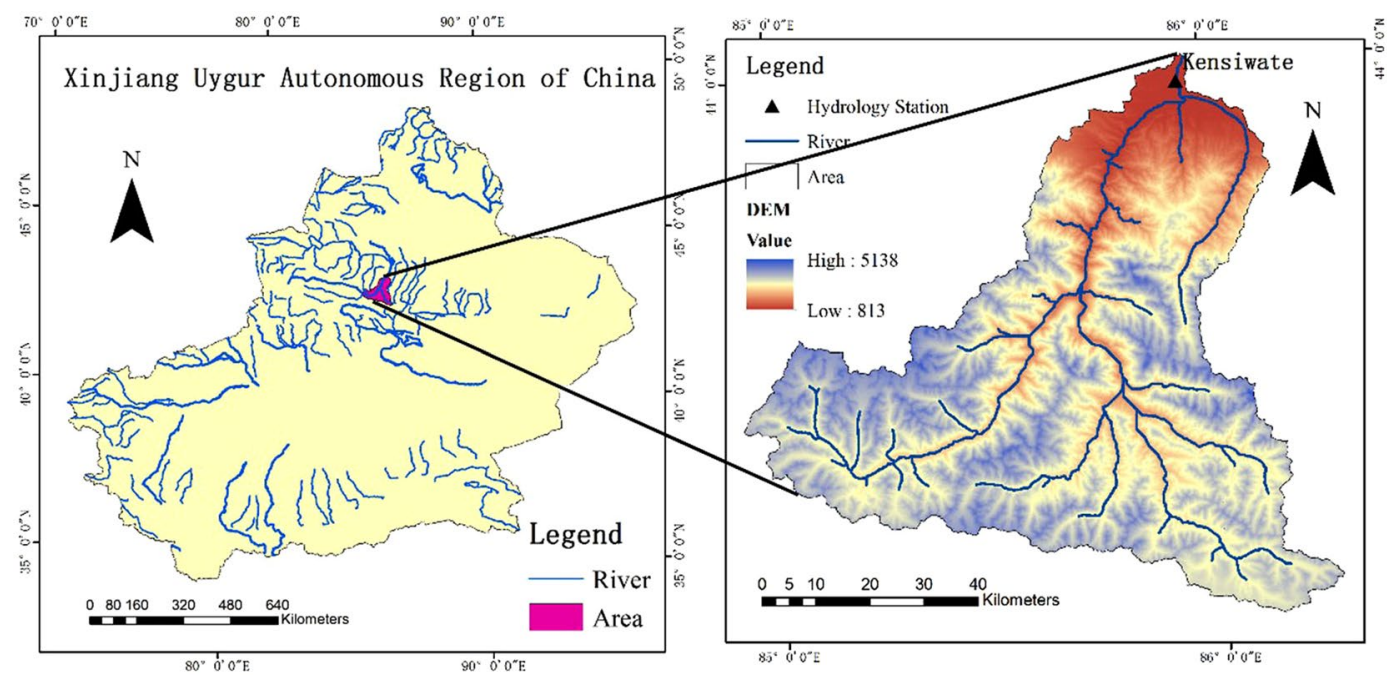

Figure 8. Sketch map of the Manas River basin and location of the hydrological stations (Note: the map was generated with data available from the Chinese Geospatial Data Cloud using ESRI's ArcGIS (version 10.1; http://www.gscloud.cn/).

\begin{tabular}{|l|l|l|}
\hline NO. & Name & Remarks \\
\hline 1 & Cultivated & Herbaceous species, Aquatic plants \\
\hline 2 & Forest & Woodland, shrub forest \\
\hline 3 & Grassland & Growing herbaceous plants \\
\hline 4 & Water & Natural land and water facilities \\
\hline 5 & $\begin{array}{l}\text { Urban and } \\
\text { buildings }\end{array}$ & $\begin{array}{l}\text { Urban and rural residential and other } \\
\text { uses, such as mining, transportation. }\end{array}$ \\
\hline
\end{tabular}

Table 4. Land use classification.

5 sensitive parameters among the 12 available parameters: the root zone maximum water storage capacity $\left(\mathrm{SR}_{\max }\right)$, initial saturated water shortage $\left(\mathrm{SR}_{0}\right)$, exponential decay rate $(\mathrm{SZM})$, effective infiltration rate $\left(\mathrm{T}_{0}\right)$, and effective overland flow runoff rate (RV).

Topographical index. Topography is an important factor for precipitation, runoff and hydrological processes in land surface ${ }^{22}$. It is also the dominant factor in the spatial distribution of temperature, precipitation, soil, and vegetation within the basin, reflecting the controlling effect of gravity on the movement of water. The topography index assumes that topography drives flows. It generally correctly predicts the accumulation of flow in topological low spots or areas where the flows accumulate. The topography index is defined as:

$$
\lambda=\ln \left(\frac{\alpha}{\tan \beta}\right)
$$

where $\lambda$ is the topography index, $\alpha$ is the upslope contributing area per unit length of contour, and $\beta$ is the topographic slope of the cell.

Suppose $A$ is the total catchment area above one point and $L$ is the width of a contour perpendicular to the direction of flow, then $\alpha=\mathrm{A} / \mathrm{L}$. The slope of local surface $(\tan \beta)$ can be calculated from direction. The first step is to analyze the flow direction, then estimate A and L in the direction. Since geometric inscribed circle method is more accurate to reflect the hydrological similarity of real catchments, the geometric inscribed circle method is adopted in this study and the calculation principle is as follows:

Suppose four grids are extracted, as shown at the bottom right corner in Fig. 10. Seen from Fig. 11, point C is the central point of the calculation grid (11). The two grids 8 and 10 are slope downwards toward point $\mathrm{C}$. We form tangents of circles A1 and A3, as shown in Fig. 11. Streamflow gathered from upslope areas moves into grid 11 and focuses on point C. Streamflow in grid 11 uniformly flows into grids 10, 8, and 7 along the downhill of conical surface. Runoff travels along the effective contour L3 and passes within the two tangents of A3, then flows into grid 8. This runoff is cumulative flow distributed from the computational grid. Other runoff goes through L2 and flows into grid 7. This part of the runoff flows into the grid in diagonal direction along the downhill grid in the main direction.

Snowmelt Module. Air temperature is the single index in the traditional snowmelt model following the energy balance model ${ }^{28}$. To ensure well performance for streamflow simulation, the improved calculation method of 


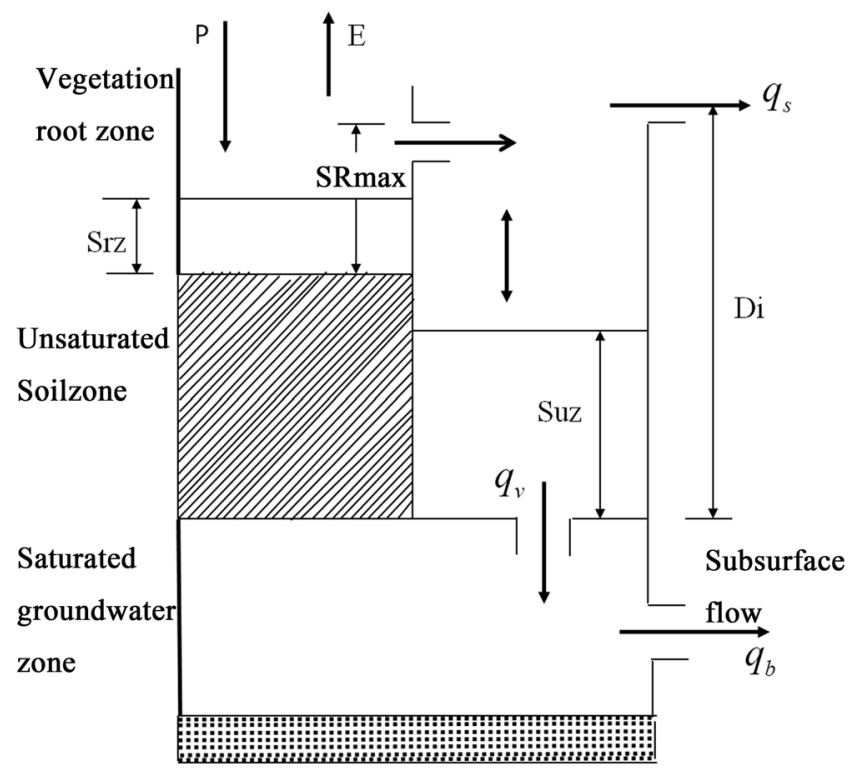

Figure 9. Diagram of TOPMODEL unit grid of soil moisture movement (Note: $P$ represents precipitation, $E$ represents the evaporation, $S_{r z}, S_{u z}$ represent vegetation root zone, unsaturated zone, respectively. $q_{v}, q_{b}, q_{s}$ are infiltration, base flow and saturated slope flow. $\mathrm{SR}_{\max }$ represents maximum water storage capacity in the root zone).

snowmelt is adopted to the snowmelt model. This method considers factors such as solar radiation and topographic features which are ignored in the traditional method. Solar radiation can be estimated without being imported by meteorological data, and the topographical factors (such as slope and slope direction) reflect the differences of spatial units. The time period is one day consistent with the usual observation of the snowmelt rate. The model is defined as:

$$
M E=\left(M F+a \frac{\text { snow }}{i c e} I\right)(T P-T B)
$$

where $M F$ is the snowmelt factor $\left(\mathrm{mm} /{ }^{\circ} \mathrm{C} \cdot \mathrm{d}\right)$, asnow is the correction coefficient of sun radiation on the snow or glacier surface, $I$ is the potential solar radiation in the surface $\left(\mathrm{W} / \mathrm{m}^{2}\right)$, and $T P$ and $T B$ are the average ambient ice surface temperatures $\left({ }^{\circ} \mathrm{C}\right)$, respectively. $M F$ and $\frac{a \text { snow }}{i c e}$ are set from prior experience, while $I$ is related to the level of solar radiation above atmosphere,

$$
I=I_{0}\left(\frac{R_{m}}{R}\right)^{2} \varphi_{a}^{\left(\frac{P}{P_{0 \cos Z}}\right)} \cos \theta
$$

where $I_{0}$ is the solar constant $\left(1368 \mathrm{~W} / \mathrm{m}^{2}\right), \frac{R_{m}}{R}$ is the coefficient of eccentricity in the Earth's orbit, where $R_{\mathrm{m}}$ is the average distance between the sun and earth, and $R$ is the instantaneous distance between the sun and earth, $\varphi_{a}$ is the average atmospheric transmittance in clear sky, and $P, P_{0}$ and $Z$ are explained below.

$$
\begin{aligned}
\frac{R_{m}}{R}= & 1.00011+0.034221 \cos \Gamma+0.00128 \sin \Gamma+0.000719 \cos 2 \Gamma \\
& +0.000077 \sin 2 \Gamma
\end{aligned}
$$

where $\Gamma$ is defined as,

$$
\Gamma=2 \pi\left(\frac{i-1}{n_{a}}\right)
$$

The transmittance in clear sky is

$$
\varphi_{a}=A+B \cos \left(2 \pi\left(\frac{i-i_{f}}{n_{a}}\right)\right)
$$

where $A$ is empirical constant (0.64) in $\varphi_{a}$; $B$ is emission factor (0.12); $i$ is day number of the year; $i_{f}$ is the day number factor in a year, in the southern hemisphere $i_{f}=174$, whereas in the northern hemisphere $i_{f}=0$; and $n_{a}$ is the number of days in a year. The atmospheric pressure is 


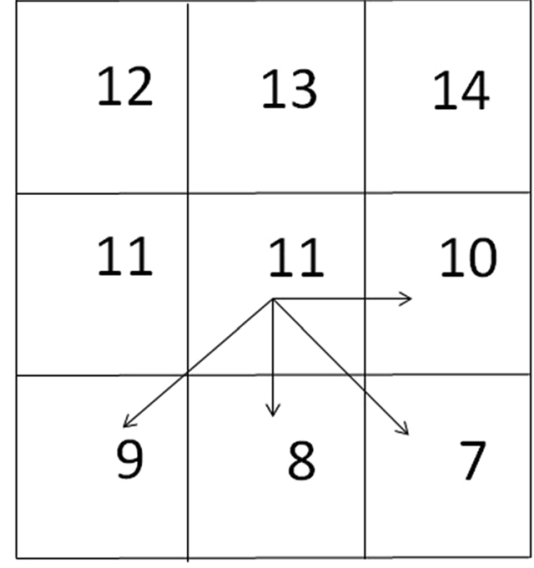

(a)

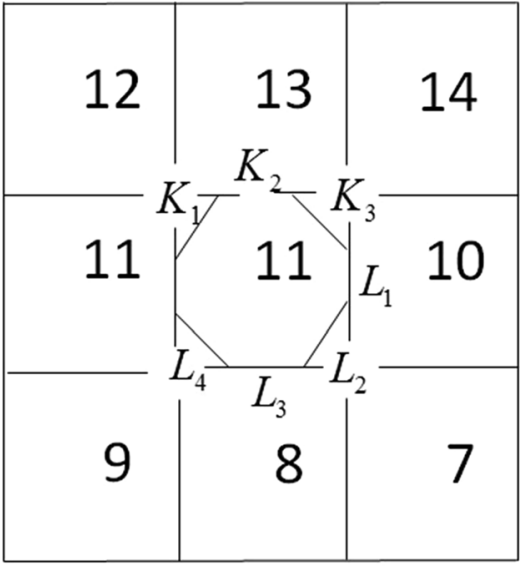

(b)

Figure 10. Multi direction flow distribution method.

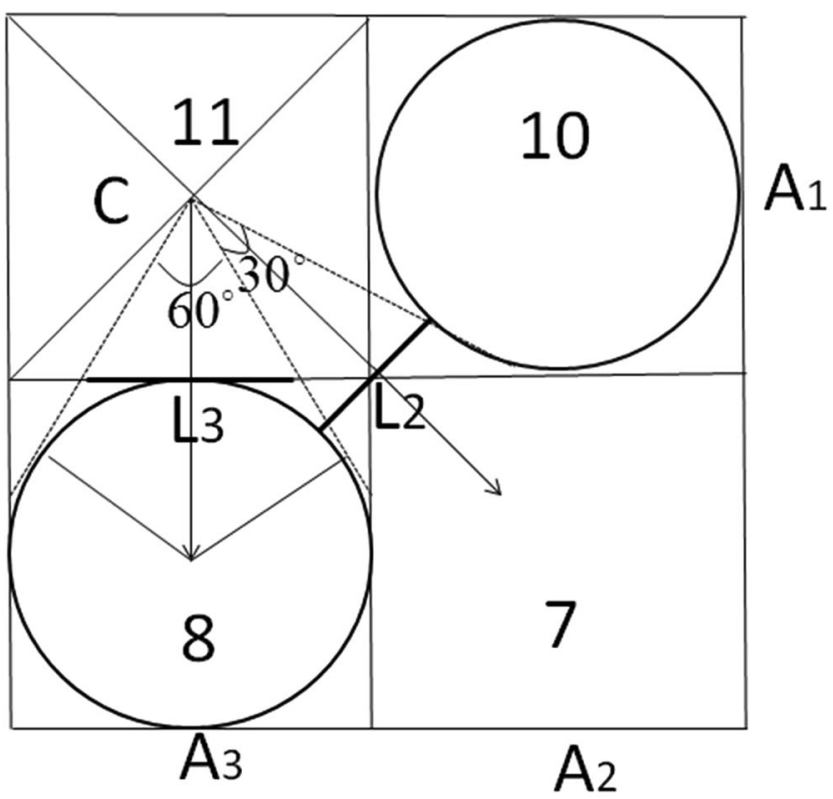

Figure 11. Geometric cone inscribed circle method of calculating the length of effective contour.

$$
\mathrm{P}=P_{0} \exp \left(-\left(\frac{g M h}{R T_{0}}\right)\right)
$$

where $P_{0}$ is the standard atmospheric pressure at sea level $(101325 \mathrm{~Pa}), g$ is acceleration of gravity $\left(9.8 \mathrm{~m} / \mathrm{s}^{2}\right), M$ is the dry air molar mass $(0.02896 \mathrm{Kg} / \mathrm{mol}), R$ is the gas constant $(8.31447 \mathrm{~J} /(\mathrm{mol} \cdot \mathrm{k}))$, and $h$ is the height above sea level in meters, $T_{0}$ is standard temperature at sea level $(288.15 \mathrm{~K})$.

The local zenith angle, $Z$, is defined by

$$
\cos Z=\sin \varphi \sin \delta+\cos \varphi \cos \delta \cos h
$$

where $\varphi$ is the latitude of the centroid point, and $\delta$ is the solar declination,

$$
\begin{aligned}
\delta= & 0.3723+23.2567 \sin \omega+0.1149 \sin 2 \omega-0.1712 \sin 3 \omega-0.7500 \cos \omega \\
& +0.3656 \cos 2 \omega+0.0201 \cos 3 \omega
\end{aligned}
$$

where $\theta$ is the angle of incidence between the normal slope and the solar beam. A widely used solution for the incidence angle is given by Garnier and Ohmura ${ }^{46}$ : 


$$
\cos \theta=\cos \beta \cos Z+\sin \beta \sin Z \cos \left(\varphi_{\text {sun }}-\varphi_{\text {slop }}\right)
$$

where $\beta$ is the angle of slope, $\varphi_{\text {sun }}$ and $\varphi_{\text {slop }}$ are the solar azimuth and the azimuth angles of slope.

GLUE approach. GLUE, an UA technique, reformulates the model calibration problem as the estimation of posterior probabilities of model response. The GLUE approach has been widely used in the forecasting uncertainty of hydrologic mathematical model ${ }^{34}$. The GLUE approach defines that the performance of simulation is not decided by one specific parameter, but by the combination of parameter sets. We therefore operated the model with a pre-set parameter distribution space, using a random sampling method to obtain a combination of model parameter values, and calculate the likelihood function between the predicted results and observation ${ }^{47}$. The selection of the critical value has certain subjectivity, in this study, the threshold criterion is defined as zero. And parameters with likelihood below this threshold are assigned to zero, that is to say, those parameters do not characterize the model's functional characteristics in a watershed.

\section{References}

1. Helton, A. M. et al. Thinking outside the channel: modeling nitrogen cycling in networked river ecosystems. Frontiers in Ecology and the Environment 9(4), 229-238 (2011).

2. Voeroesmarty, C. J. et al. Global threats to human water security and river biodiversity. Nature 467(7315), 555-561 (2010).

3. Woodward, G. et al. Continental-scale effects of nutrient pollution on stream ecosystem functioning. Science 336(6087), 1438-1440 (2012).

4. Yu, Z., Lue, H., Zhu, Y., Drake, S. \& Liang, C. Long-term effects of revegetation on soil hydrological processes in vegetation-stabilized desert ecosystems. Hydrological Processes 24(1), 87-95 (2010).

5. Cho, K. H. et al. Modeling seasonal variability of fecal coliform in natural surface waters using the modified SWAT. Journal of Hydrology 535, 377-385 (2016).

6. Pereira, D. D. R., Martinez, M. A., Pruski, F. F. \& Silva, D. D. D. Hydrological simulation in a basin of typical tropical climate and soil using the SWAT model part I: calibration and validation tests. Journal of Hydrology: Regional Studies 7, 14-37 (2016).

7. Wang, W. et al. A quantitative analysis of hydraulic interaction processes in stream-aquifer systems. Scientific Reports $\mathbf{6}, 19876$ (2016).

8. Ma, Y. et al. Hydrological cycle and water balance estimates for the megadune-lake region of the Badain Jaran Desert, China. Hydrological Processes 31(18), 3255-3268 (2017).

9. Xia, J., Zhang, Y., Zhan, C. \& Ye, A. Z. Water quality management in China: the case of the Huai River Basin. International Journal of Water Resources Development 27(1), 167-180 (2011).

10. Akter, A. \& Babel, M. S. Hydrological modeling of the Mun River basin in Thailand. Journal of Hydrology 452, 232-246 (2012).

11. Ebel, B. A. \& Loague, K. Physics-based hydrologic-response simulation: Seeing through the fog of equifinality. Hydrological Processes 20(13), 2887-2900 (2006).

12. Fonseca, A., Botelho, C., Boaventura, R. A. \& Vilar, V. J. Integrated hydrological and water quality model for river management: a case study on Lena River. Science of the Total Environment 485, 474-489 (2014).

13. Nasr, A. et al. A comparison of SWAT, HSPF and SHETRAN/GOPC for modelling phosphorus export from three catchments in Ireland. Water Research 41(5), 1065-1073 (2007).

14. Tarboton, D. G. A new method for the determination of flow directions and upslope areas in grid digital elevation models. Water Resources Research 33(2), 309-319 (1997).

15. Xie, H. \& Lian, Y. Uncertainty-based evaluation and comparison of SWAT and HSPF applications to the Illinois River Basin. Journal of Hydrology 481, 119-131 (2013).

16. Huang, P., Li, Z., Chen, J., Li, Q. \& Yao, C. Event-based hydrological modeling for detecting dominant hydrological process and suitable model strategy for semi-arid catchments. Journal of Hydrology 542, 292-303 (2016).

17. Liu, S., Xu, J., Zhao, J. \& Hou, P. Applicability of modified TOPMODEL in the arid zone and the humid zone. Applied Mechanics and Materials 423-426, 1418-1421 (2013).

18. Guo F., Liu X. R. \& Ren L. L. A topography based hydrological model: topmodel and its widened application. Advances in Waterence (2000).

19. Mendicino, G. \& Sole, A. The information content theory for the estimation of the topographic index distribution used in TOPMODEL. Hydrological Processes 11(9), 1099-1114 (1997).

20. Tran Van, T., Sunada, K. \& Ichikawa, Y. Water resources management under future development and climate change impacts in the Upper Srepok River Basin, Central Highlands of Vietnam. Water Policy 14(5), 725-745 (2012).

21. Wolock D. M. Simulating the variable source area concept of streamflow generation with the watershed model topmodel. WaterResources Investigations Report 93-4124 (1993).

22. Ambroise, B., Beven, K. \& Freer, J. Toward a generalization of the TOPMODEL concepts: topographic indices of hydrological similarity. Water Resources Research 32(7), 2135-2145 (1996).

23. Beven, K. J., Kirkby, M. J., Schofield, N. \& Tagg, A. F. Testing a physically-based flood forecasting model (topmodel) for three U.K. catchments. Journal of Hydrology 69(1), 119-143 (1984).

24. Yong, B., Zhang, W., Niu, G., Ren, L. \& Qin, C. Spatial statistical properties and scale transform analyses on the topographic index derived from DEMs in China. Computers \& Geosciences 35(3), 592-602 (2009).

25. Costa-Cabral, M. C. \& Burges, S. J. Digital elevation model networks (demon): a model of flow over hillslopes for computation of contributing and dispersal areas. Water Resources Research 30(6), 1681-1692 (1994).

26. Essery, R., Li, L. \& Pomeroy, J. A distributed model of blowing snow over complex terrain. Hydrological Processes 13(14-15), 2423-2438 (1999).

27. Xie, P., Zhu, Y., Chen, G., Lei, H. \& Li, J. A lumped watershed hydrological model considering land use and land cover change and its application. Journal of Mountain Science 25(3), 257-264 (2007).

28. Zhao, Q. et al. Research advance of snowmelt model. Xinjiang Agricultural Sciences 44(6), 734-739 (2007).

29. Bronstert, A. \& Bardossy, A. Uncertainty of runoff modelling at the hillslope scale due to temporal variations of rainfall intensity. Physics and Chemistry of the Earth 28(6-7), 283-288 (2003).

30. Gaume, E., Villeneuve, J. P. \& Desbordes, M. Uncertainty assessment and analysis of the calibrated parameter values of an urban storm water quality model. Journal of Hydrology 210(1-4), 38-50 (1998).

31. Guo S. Uncertainty analysis of impact of climate change on hydrology and water resources. Hydrology (1995).

32. Mandal, S. \& Simonovic, S. P. Quantification of uncertainty in the assessment of future streamflow under changing climate conditions. Hydrological Processes 31(11), 2076-2094 (2017).

33. Aronica, G., Bates, P. D. \& Horritt, M. S. Assessing the uncertainty in distributed model predictions using observed binary pattern information within GLUE. Hydrological Processes 16(10), 2001-2016 (2002). 
34. Beven, K. \& Binley, A. The future of distributed models: model calibration and uncertainty prediction. Hydrological Processes 6(3), $279-298$ (1992)

35. Meng, X. et al. Hydrological modeling in the Manas River Basin using soil and water assessment tool driven by CMADS. Tehnicki Vjesnik-Technical Gazette 24(2), 525-534 (2017).

36. Perrin, C., Michel, C. \& Andreassian, V. Does a large number of parameters enhance model performance? Comparative assessment of common catchment model structures on 429 catchments. Journal of Hydrology 242(3-4), 275-301 (2001).

37. Ren L. et al. Study on variations in climatic variables and their influence on runoff in the Manas River Basin, China. Water 9(4) (2017).

38. Xue L. et al. Identification of potential impacts of climate change and anthropogenic activities on streamflow alterations in the Tarim River Basin, China. Scientific Reports 7 (2017).

39. Feng, H., Zou, B. \& Luo, J. Coverage-dependent amplifiers of vegetation change on global water cycle dynamics. Journal of Hydrology 550, 220-229 (2017).

40. Dai, Z., Liu, J. T., Wei, W. \& Chen, J. Detection of the Three Gorges Dam influence on the Changiiang (Yangtze River) submerged delta. Scientific Reports 4, 6600 (2014).

41. Xue L., Zhang H., Yang C., Zhang L. \& Sun C. Quantitative assessment of hydrological alteration caused by irrigation projects in the Tarim River basin, China. Scientific Reports 7 (2017).

42. Xue, L., Zhang, H., Zhang, L., Chi, Y. \& Sun, C. Impact of water conservancy projects on eco-hydrological regime of Tarim River based on improved RVA method. Journal of Hohai University (Natural Sciences) 45(3), 1-8 (2017).

43. Xue, L., Zhang, H., Zhang, L., Chi, Y. \& Sun, C. Changes in characteristics of environmental flow in Tarim irrigation area before and after water diversion. Water Resources Protection 33(3), 31-37 (2017).

44. Brown, A. E., Zhang, L., McMahon, T. A., Western, A. W. \& Vertessy, R. A. A review of paired catchment studies for determining changes in water yield resulting from alterations in vegetation. Journal of Hydrology 310(1-4), 28-61 (2005).

45. Beven, K. J. \& Kirkby, M. J. A physically based, variable contributing area model of basin hydrology/Un modèle à base physique de zone d'appel variable de l'hydrologie du bassin versant. Hydrological Sciences Bulletin 24(1), 43-69 (1979).

46. Garnier, B. J. \& Ohmura, A. A Method of Calculating the Direct Shortwave Radiation Income of Slopes. Journal of Applied Meteorology 7(5), 796-800 (1968).

47. Freer, J., Beven, K. \& Ambroise, B. Bayesian estimation of uncertainty in runoff prediction and the value of data: An application of the GLUE approach. Water Resources Research 32(7), 2161-2173 (1996).

\section{Acknowledgements}

This study was supported by the National Scientific Foundation of China (NSFC) (No. 51779074, No. 41371052). Ministry of Water Resources' special funds for scientific research on public causes (201501059) and State's Key Project of Research and Development Plan (2017YFC0404304) and Jiangsu water conservancy science and technology project (2017027). The authors are very grateful to the supporting sponsored by Qing Lan Project of Jiangsu Province and Jiangsu Province outstanding young teachers and principals overseas training program[2015]35.

\section{Author Contributions}

Lianqing Xue and Fan Yang conceived and designed the research themes; Fan Yang, Wenqian Li and Changbing Yang analyzed the data; Fan Yang, Guanghui Wei and Xinlin He contributed to data; Lianqing Xue wrote the paper. All authors have contributed to the revision and approved the manuscript.

\section{Additional Information}

Competing Interests: The authors declare that they have no competing interests.

Publisher's note: Springer Nature remains neutral with regard to jurisdictional claims in published maps and institutional affiliations.

(c) (i) Open Access This article is licensed under a Creative Commons Attribution 4.0 International License, which permits use, sharing, adaptation, distribution and reproduction in any medium or format, as long as you give appropriate credit to the original author(s) and the source, provide a link to the Creative Commons license, and indicate if changes were made. The images or other third party material in this article are included in the article's Creative Commons license, unless indicated otherwise in a credit line to the material. If material is not included in the article's Creative Commons license and your intended use is not permitted by statutory regulation or exceeds the permitted use, you will need to obtain permission directly from the copyright holder. To view a copy of this license, visit http://creativecommons.org/licenses/by/4.0/.

(C) The Author(s) 2017 